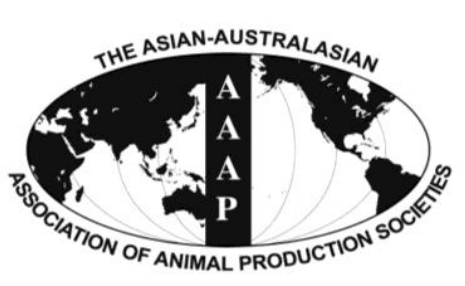

Open Access

Asian Australas. J. Anim. Sci.

Vol. 27, No. 12 : 1721-1725 December 2014

http://dx.doi.org/10.5713/ajas.2014.14216

www.ajas.info

pISSN 1011-2367 elSSN 1976-5517

\title{
Effects of Coconut Materials on In vitro Ruminal Methanogenesis and Fermentation Characteristics
}

\author{
E. T. Kim ${ }^{\text {a }}$, C. G. Park ${ }^{1, a}$, D. H. Lim, E. G. Kwon, K. S. Ki, S. B. Kim ${ }^{2}$, Y. H. Moon ${ }^{3}$, N. H. Shin ${ }^{4}$, and S. S. Lee ${ }^{5}$ * \\ Dairy Science Division, National Institute of Animal Science, Rural Development Administration, \\ Cheonan 331-808, Korea
}

\begin{abstract}
The objective of this study was to evaluate the in vitro effects of coconut materials on ruminal methanogenesis and fermentation characteristics, in particular their effectiveness for mitigating ruminal methanogenesis. Fistulated Holstein cows were used as the donor of rumen fluid. Coconut materials were added to an in vitro fermentation incubated with rumen fluid-buffer mixture and timothy substrate for $24 \mathrm{~h}$ incubation. Total gas production, gas profiles, total volatile fatty acids (tVFAs) and the ruminal methanogens diversity were measured. Although gas profiles in added coconut oil and coconut powder were not significantly different, in vitro ruminal methane production was decreased with the level of reduction between $15 \%$ and $19 \%$ as compared to control, respectively. Coconut oil and coconut powder also inhibited gas production. The tVFAs concentration was increased by coconut materials, but was not affected significantly as compared to control. Acetate concentration was significantly lower $(\mathrm{p}<0.05)$, while propionate was significantly higher $(\mathrm{p}<0.05)$ by addition of the coconut materials than that of the control. The acetate:propionate ratio was significantly lowered with addition of coconut oil and coconut powder $(\mathrm{p}<0.05)$. The methanogens and ciliate-associated methanogens in all added coconut materials were shown to decrease as compared with control. This study showed that ciliate-associated methanogens diversity was reduced by more than $50 \%$ in both coconut oil and coconut powder treatments. In conclusion, these results indicate that coconut powder is a potential agent for decreasing in vitro ruminal methane production and as effective as coconut oil. (Key Words: Ruminal Methane Production, Relative Quantification, Real-time Polymerase Chain Reaction, Coconut, Methanogens)
\end{abstract}

\section{INTRODUCTION}

Ruminal methane emission has been an important topic worldwide due to its effect on global warming. During anaerobic enteric fermentation in the rumen, the methane

\footnotetext{
* Corresponding Author: Sung Sill Lee. Tel: +82-55-772-1883, Fax: +82-55-772-1889, E-mail: 1ss@ gnu.ac.kr

${ }^{1}$ Resources Development Institute, Seoul 134-851, Korea.

${ }^{2}$ Rural Development Administration, Jeonju 560-550, Korea.

${ }^{3}$ Department of Animal Science and Biotechnology, Gyeongnam

National University of Science and Technology, Jinju 660-758, Korea.

${ }^{4}$ Gyengsangnamdo Livestock Veterinary Research Institute, Sancheong 666-962, Korea.

5 Division of Applied Life Science, Graduate School of Gyeongsang National University (Institute of Agriculture and Life Science), Jinju 660-701, Korea.

${ }^{a}$ These authors contributed equally to the work.

Submitted Mar. 26, 2014; Revised May 19, 2014; Accepted Aug. 31, 2014
}

produced is a large contributor of non- $\mathrm{CO}_{2}$ greenhouse gas emissions as well as a substantial loss of between 2 and $12 \%$ of the gross energy intake (Johnson and Johnson, 1995). Ruminant nutritionists have studied essential oils (Calsamiglia et al., 2007), plant secondary metabolites (Woodward et al., 2001; Patra et al., 2006) and dietary lipids (Beauchemin et al., 2007) as rumen manipulators to improve ruminal fermentation characteristics as well as potential anti-methanogenic feed additives. Dohme et al. (2001) reported the effects of fatty acids on ruminal fermentation using the rumen simulation technique (RUSITEC) were to inhibit methane production and methanogenic counts. Coconut oil containing lauric acid (LA) has developed as potent alternative to reduce ruminal methane emission without causing adverse effects on ruminal fermentation. Researchers have examined the effect of coconut oil on methane emission and methanogens population in vitro as well as in vivo (Machmüller and 
Kreuzer, 1999; Machmüller et al., 2003; Jordan et al., 2006; Ding et al., 2012). In particular, Dong et al. (1997) showed that the addition of $3 \%$ and $6 \%$ of coconut oil was more effective at inhibiting ruminal methanogenesis than whole crushed oilseeds in vitro. In addition, Pilajun and Wanapat (2013) reported that coconut oil supplementation could improve ruminal fermentation of swamp buffalo with reducing methane emissions and changing of microbial populations. In a previous study, Newbold and Chamberlain (1988) presented that coconut oil inhibited the protozoa in the rumen. Furthermore, Yabuuchi et al. (2006) examined ruminal fermentation with soy oil and palm oil as longchain fatty acid triglycerides, palm kernel oil, coconut oil, powdered coconut oil and coconut oil calcium salt as medium chain LA-rich oils. Some LA-rich oils and free LA inhibited ruminal methanogenesis and increased volatile fatty acid (VFA) production, especially propionate in a culture with ground corn. It is similar to that observed with ionophores in rumen fermentation. However, there is limited data on manipulating ruminal methanogenesis using coconut powder.

The present study was conducted to evaluate the effect of coconut oil and coconut powder supplementation on ruminal methane production, fermentation and methanogens population in in vitro.

\section{MATERIALS AND METHODS}

\section{Coconut materials and ruminal in vitro incubation}

Preparation of additives: The desiccated coconut powder was pressed out after dehusking coconut fat and oil used for this study. Fully ripen coconuts about 12 months were used for the preparation of desiccated coconut powder. The coconuts were dehusked and their shells were removed. The white portion of nuts called endocarp was removed by scrapping. The coconut endocarp was broken into pieces of 1 inch size. The powdered coconut was then dried in a drier by spreading it out uniformly in trays. The temperature in the drying chamber was maintained at about $82^{\circ} \mathrm{C}$, and hot air was passed through powdered coconut for more than an hour to aid evaporation. When powder was dried, it was cooled and then passed through a vibratory screen having a 16 mesh size. Coconut materials used in this study were obtained from Resources Development Institute in Korea.

In vitro incubation: Fistulated Holstein cows were used as the donors of rumen fluid. Timothy and commercial concentrate (AMINOTEK, Cheiljedang, Seoul, Korea) in the ratio of 60:40 were fed at $2 \%$ of body weight twice a day (09:00 and 18:00 h). Water and mineral-vitamin block were allowed ad libitum. The rumen fluid was collected from the fistulated Holstein cow before morning feeding. Rumen liquor was filtered through four layers of cheesecloth before mixing with buffer maintained at $39^{\circ} \mathrm{C}$.
The $30 \mathrm{~mL}$ of rumen fluid-buffer mixture, comprising McDougall buffer (McDougall, 1948) and rumen liquor in the ratio of 4 to 1 , was dispensed anaerobically into $120 \mathrm{~mL}$ serum bottles containing $0.3 \mathrm{~g}$ of timothy substrate with coconut oil and coconut oil powder (3\% of total volume of rumen fluid-buffer mixture (v/v), respectively). The serum bottles were filled with $\mathrm{O}_{2}$-free $\mathrm{N}_{2}$ gas capped with a rubber stopper and held in a shaking incubator (120 rpm, HBS201SL, HANBAEK, Bucheon, Korea) at $39^{\circ} \mathrm{C}$ for $24 \mathrm{~h}$.

\section{Ruminal fermentation characteristics}

Gas production: At the end of incubation, total gas production was measured by the assay of Theodorou et al. (1994). A detachable pressure transducer and a digital readout voltmeter (Laurel Electronics, Inc., Costa Mesa, CA, USA) were used to measure the headspace gas pressure of fermenting cultures. For total gas production measurement, the transducer was modified in such a way that it could be linked to the inlet of a disposable Luer-lock three-way stopcock (Theodorou, 1994). Gas pressure in the headspace was read from the display unit after insertion of the hypodermic syringe needle through the butyl rubber stopper above the culture medium.

Gas profiles assay and volatile fatty acid (VFA): The headspace gas in the serum bottle was collected for analyzing methane, carbon dioxide and hydrogen by gas chromatography (GC-2010, Shimadzu, Kyoto, Japan) equipped with column (Shincarbon ST. 50/80, Shimadzu, Kyoto, Japan). The culture was subsampled for analysis of pH (Mettle-Toledo, MP220, Greifensee, Switzerland). The incubated samples were centrifuged at $10,000 \mathrm{rpm}$ for 10 min. After centrifugation, the supernatant liquid was treated with $25 \%$ meta-phosphoric acid at a ratio of 5 parts the supernatant to 1 part acid. Tubes were then covered, mixed, and allowed to stand at room temperature for $30 \mathrm{~min}$. The mixture was centrifuged at $12,000 \mathrm{rpm}$ for $20 \mathrm{~min}$, and then a $1 \mathrm{~mL}$ aliquot of supernatant added to a gas chromatogram vial and placed in the autoanalyzer. The VFA concentration was determined by a gas chromatography (GC-2010, Shimadzu, Kyoto, Japan) using a modification of the methods described by Erwin et al. (1961).

\section{Quantitative polymerase chain reaction assays \\ DNA extraction: Qiagen Retsch TissueLyser (MM300,} San Diego, CA, USA), a high-speed reciprocal shaker which retains samples in screw-capped tubes containing silica beads, was used for DNA extraction. Total nucleic acid was extracted from the incubated rumen samples using the modified bead-beating protocol with the QIAamp DNA mini kit (250) (QIAGEN, Valencia, CA, USA). The samples consisted of a $1.0 \mathrm{~mL}$ aliquot taken from the $30 \mathrm{~mL}$ incubated culture using a wide bore pipette so as to ensure a 
homogenous sample containing fluid and digesta. Nucleic acid concentrations were measured by using a NanoDrop Spectrophotometer (ND-1000, Wilmington, DE, USA).

Polymerase chain reaction primers: The polymerase chain reaction (PCR) primer sets used in this study for amplification of methanogenic archaea, ciliate-associated methanogens and methanogens were the same as referenced by Luton et al. (2002), Medlin et al. (1998) and Denman et al. (2007), respectively as shown in Table 1.

Real-time polymerase chain reaction: Quantitative PCR assays for enumeration of ciliate-associated methanogens and methanogens were performed according to the methods described by Denman and McSweeney (2006) and Denman et al. (2007), respectively, on a real-time PCR Machine (Rotor-Gene, Crobett life science, Australia) using the iQ SYBR Green Supermix (Bio-Rad Inc., Hercules, CA, USA). The values of cycle threshold $(\mathrm{Ct})$ after real-time PCR were used to determine fold change (Normalized Fold Expression) of different microbial population relative to control without additives. Abundance of these microbes was expressed by the equation: relative quantification = $2^{-\Delta \mathrm{Ct}(\text { Target) }-\Delta \mathrm{Ct}(\mathrm{Control})}$, where $\mathrm{Ct}$ represents threshold cycle. All quantitative (q) PCR reaction mixture (final volume of $25 \mu \mathrm{L}$ ) contained forward and reverse primers, the iQ SYBR Green Supermix and DNA template. A negative control without the template DNA was used in every qPCR assay for each primer. The PCR conditions including the annealing and the extension temperature were as shown in references (Table 1).

\section{Statistical analysis}

Data were analyzed using the general linear model procedure of the Statistical Analysis System Institute, Inc. (SAS, 2002). The effects of coconut oil and coconut oil powder on total gas production, gas profiles, $\mathrm{pH}$, and VFA were compared to the controls and significant differences between treatment means were examined using Duncan's multiple comparison tests. A $\mathrm{p}<0.05$ was considered to indicate statistical significance. All analyses were carried out using statistical analysis systems (SAS) (2002).

\section{RESULTS AND DISCUSSION}

Effects of coconut materials on in vitro ruminal
Table 2. The in-vitro effect of coconut materials on total gas production, gas profiles after $24 \mathrm{~h}$ incubation

\begin{tabular}{lcccc}
\hline Item & Control & $\begin{array}{c}\text { Coconut } \\
\text { oil }\end{array}$ & $\begin{array}{c}\text { Coconut } \\
\text { powder }\end{array}$ & SEM \\
\hline Total gas $(\mathrm{mL} / \mathrm{g} \mathrm{DM})$ & 228.30 & 214.83 & 217.63 & 3.15 \\
$\mathrm{CH}_{4}(\mathrm{~mL} / \mathrm{g} \mathrm{DM})$ & 35.93 & 29.10 & 30.53 & 1.63 \\
$\mathrm{CO}_{2}(\mathrm{~mL} / \mathrm{g} \mathrm{DM})$ & 110.37 & 107.33 & 113.57 & 3.95 \\
\hline
\end{tabular}

SEM, standard error of the mean; DM, dry matter.

Hydrogen was not detected.

Means in the same row with different superscripts differ significantly $(\mathrm{p}<0.05)$.

\section{fermentation characteristics}

The effect of coconut materials on total gas production and gas profiles are given in Table 2. Total gas production and gas profiles in added coconut oil and coconut powder were not significantly different $(\mathrm{p}<0.05)$, but in vitro ruminal methane production was decreased as compared to control without treatment, respectively (Table 2). Hydrogen produced during enteric fermentation is known as the precursor of ruminal methane emission, and the regulation of hydrogen is the key to control methane emission in the rumen (Mitsumori and Sun, 2008). However, there was not enough hydrogen gas produced to detect in this in vitro study. This result indicated that hydrogen produced during in vitro ruminal fermentation in this study might be nearly all utilized in the pathway for formation of propionate. In addition, hydrogen production is closely related with anaerobic ciliates (Vogels et al., 1980). The result of ciliateassociated methaogens diversity was shown to be decrease in this study (Figure 1). Total volatile fatty acids (tVFAs) concentration was increased by the addition of coconut materials, but was not affected significantly as compared to control. Acetate concentration was significantly lower $(\mathrm{p}<0.05)$, while propionate was significantly higher $(p<0.05)$ than that of the control (Table 3). Thus, the acetate:propionate (a:p) ratio was significantly lowered $(\mathrm{p}<0.05)$ by the addition coconut oil and coconut powder when compared to control. In particular, ruminal methane production is closely related to the a:p ratio, and the reduced methane production led to a higher molar proportion of propionate and low a:p ratio (Nellet et al., 1997; Mitsumori and Sun, 2008). Especially, acetate and butyrate accelerate ruminal methane emission while the formation of propionate is considered as a competitive

Table 1. Oligonucleotide primer sets used for real-time PCR assay

\begin{tabular}{lll}
\hline Target group & \multicolumn{1}{c}{ Sequence (5'-3') } & Reference \\
\hline Methanogenic archaea & F: GGTGGTGTMGGATTCACACARTAYGCWACAGC & Luton et al. (2002) \\
& R: TTCATTGCRTAGTTWGGRTAGTT & Medlin et al. (1988) \\
Ciliate-associated & F: AGGAATTGGCGGGGGAGCAC & \\
methanogens & R: TGTGTGCAAGGAGCAGGGAC & Denman et al. (2007) \\
Methanogens & F: TTCGGTGGATCDCARAGRGC & \\
\hline
\end{tabular}

$\mathrm{PCR}$, polymerase chain reaction; $\mathrm{F}$, forward; $\mathrm{R}$, reverse. 


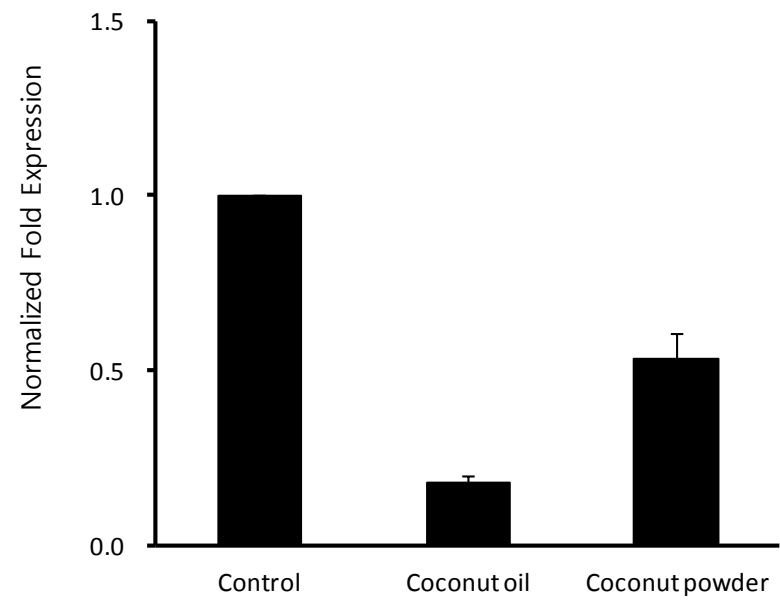

(a) Methanogens

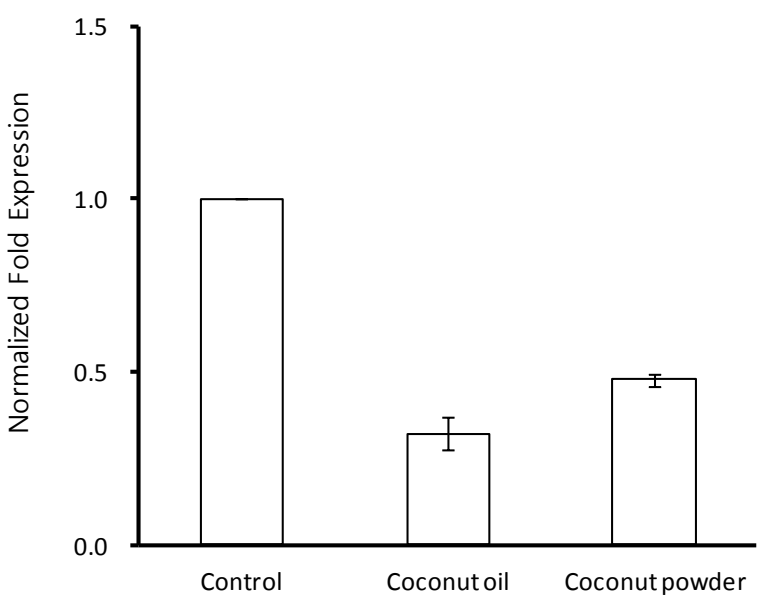

(b) Ciliate-associated methanogens

Figure 1. (a) Relative quantification analysis of methanogens and (b) ciliate-associated methanogens in vitro ruminal fermentation by the addition of coconut materials after $24 \mathrm{~h}$ incubation.

pathway for hydrogen use in the rumen.

Effects of coconut materials on in vitro ruminal methanogens diversity

The effect of coconut materials on ruminal methanogens and ciliate-associated methanogen communities is shown in Figure 1(a, b). The methanogens and ciliate-associated methanogens diversities in all added coconut materials were shown to decrease as compared with control. Methanogens living on and within rumen ciliate protozoa may account for up to $37 \%$ of the ruminal methane production, and the removal protozoa led to a reduction in the ruminal methane production by an average of $13 \%$ although there is difference according to diets (Hegarty, 1999). In addition, Newbold et al. (1995) also reported that the methanogens associated with rumen ciliate protozoa accounted for $9 \%$ to $25 \%$ of ruminal methanogenesis. Pilajun and Wanapat (2013) reported that total bacteria population was increased by coconut oil supplementation, whereas protozoa community was reduced by coconut oil supplementation in

Table 3. The in-vitro effect of coconut materials on ruminal fermentation characteristics after $24 \mathrm{~h}$ incubation

\begin{tabular}{lcccc}
\hline Item & Control & Coconut oil & $\begin{array}{c}\text { Coconut } \\
\text { powder }\end{array}$ & SEM \\
\hline pH & $6.65^{\mathrm{a}}$ & $6.45^{\mathrm{b}}$ & $6.55^{\mathrm{ab}}$ & 0.09 \\
tVFA $(\mathrm{mM})$ & 63.95 & 64.62 & 65.06 & 1.59 \\
Acetate $(\mathrm{mM})$ & $42.01^{\mathrm{a}}$ & $32.27^{\mathrm{b}}$ & $33.52^{\mathrm{b}}$ & 4.37 \\
Propionate $(\mathrm{mM})$ & $12.37^{\mathrm{c}}$ & $16.75^{\mathrm{a}}$ & $14.55^{\mathrm{b}}$ & 1.89 \\
Butyrate $(\mathrm{mM})$ & $6.21^{\mathrm{c}}$ & $9.20^{\mathrm{b}}$ & $10.57^{\mathrm{a}}$ & 1.82 \\
A:P ratio & $3.40^{\mathrm{a}}$ & $1.93^{\mathrm{c}}$ & $2.31^{\mathrm{b}}$ & 0.63 \\
\hline
\end{tabular}

tVFA, total volatile fatty acid; A:P ratio, acetate:propionate ratio; SEM, standard error of the mean.

${ }^{a-c}$ Means in the same row with different superscripts differ significantly $(\mathrm{p}<0.05)$. in vivo experiments. Furthermore, Dohme et al. (2000, 2001) also studied the inhibitive effects of oils rich in medium-chain fatty acids such as coconut oil on methane production by suppressing ruminal methanogens and ciliate. The methane-inhibiting effect of coconut oil was most effective against ruminal methanogenic diversity with a changed metabolic activity (Machmüller et al., 2003). This in vitro study showed that ciliate-associated methanogens diversity was reduced by more than $50 \%$ in coconut oil and coconut powder treatments (Figure 1). Ciliate protozoa have an important role in ruminal methanogenesis due to their relationship with methanogens which attach to their surface. The finding in this study that coconut oil and coconut powder reduced the ciliated-associated methanogens diversity agrees with evidence that protozoa-free ruminants have decreased ruminal methanogenesis. Besides, coconut oil and coconut powder also decreased the methanogen population by $80 \%$ and $50 \%$, respectively (Figure 1). Ding et al. (2012) reported that coconut oil was effective in inhibiting ruminal methanogenesis. Machmüller and Kreuzer (1999) suggested that coconut oil is a promising natural additive for reducing the ruminal methane release without adverse effects on ruminal fermentation. In conclusion, these results indicate that coconut powder is a potential agent for decreasing in vitro ruminal methane production and as effective as coconut oil. In future, a dose response assay should be conducted to determine a suitable dose of coconut powder for mitigating ruminal methanogenesis.

\section{ACKNOWLEDGMENTS}

E. T. Kim was supported by 2014 Postdoctoral Fellowship Program of National Institute of Animal Science, 
Rural Development Administration, Republic of Korea.

\section{REFERENCES}

Beauchemin, K. A., S. M. McGinn, and H. V. Petit. 2007. Methane abatement strategies for cattle: lipid supplementation of diets. Can. J. Anim. Sci. 87:431-440.

Calsamiglia, S., M. Busquet, P. W. Cardozo, L. Castillejos, and A. Ferret. 2007. Invited review: Essential oils as modifiers of rumen microbial fermentation. J. Dairy Sci. 90:2580-2595.

Denman, S. E. and C. S. McSweeney. 2006. Development of a real-time PCR assay for monitoring anaerobic fungal and cellulolytic bacterial populations within the rumen. FEMS Microbiol. Ecol. 58:572-582.

Denman, S. E., N. W. Tomkins, and C. S. McSweeney. 2007. Quantitation and diversity analysis of ruminal methanogenic populations in response to the antimethanogenic compound bromochloromethane. FEMS Microbiol. Ecol. 62:313-322.

Ding, X., R. Long, Q. Zhang, X. Huang, X. Guo, and J. Mi. 2012. Reducing methane emissions and the methanogen population in the rumen of Tibetan sheep by dietary supplementation with coconut oil. Trop. Anim. Health Prod. 44:1541-1545.

Dohme, F., A. Machmüller, A. Wasserfallen, and M. Kreuzer. 2000. Comparative efficiency of various fats rich in medium-chain fatty acids to suppress ruminal methanogenesis as measured with RUSITEC. Can. J. Anim. Sci. 80:473-484.

Dohme, F., A. Machmüller, A. Wasserfallen, and M. Kreuzer. 2001. Ruminal methanogenesis as infuenced by individual fatty acids supplemented to complete ruminant diets. Lett. Appl. Microbiol. 32:47-51.

Erwin, E. S., G. J. Marco, and E. M. Emery. 1961. Volatile fatty acid analysis of blood and rumen fluid by gas chromatography. J. Dairy Sci. 44:1768-1771.

Hegarty, R. S. 1999. Reducing rumen methane emissions through elimination of rumen protozoa. Aust. J. Agric. Res. 50:13211328.

Johnson, K. A. and D. E. Johnson. 1995. Methane emissions from cattle. J. Anim. Sci. 73:2483-2492.

Jordan, E., D. K. Lovett, M. Hawkins, J. J. Callan, and F. P. O'Mara. 2006. The effect of varying levels of coconut oil on intake, digestibility and methane output from continental cross beef heifers. Anim. Sci. 82:859-865.

Luton, P. E., J. M. Wayne, R. J. Sharp, and P. W. Riley. 2002. The mcrA gene as an alternative to 16S rRNA in the phylogenetic analysis of methanogen populations in landfill. Microbiology 148:3521-3530.
Machmüller, A. and M. Kreuzer. 1999. Methane suppression by coconut oil and associated effects on nutrient and energy balance in sheep. Can. J. Anim. Sci. 79:65-72.

Machmüller, A., C. R. Soliva, and M. Kreuzer. 2003. Effect of coconut oil and defaunation treatment on methanogenesis in sheep. Reprod. Nutr. Dev. 43:41-55.

McDougall, E. I. 1948. Studies on ruminant saliva. 1. The composition and output of sheep's saliva. Biochem. J. 43:99109.

Medlin, L., H. J. Elwood, S. Stickel, and H. L. Sogin. 1988. The characterization of enzymatically amplified eukaryotic 16Slike rRNA-coding regions. Gene 71:491-499.

Mitsumori, M. and W. Sun. 2008. Control of rumen microbial fermentation for mitigating methane emissions from the rumen. Asian Australas. J. Anim. Sci. 21:144-154.

Newbold, C. J. and D. G. Chamberlain. 1988. Lipids are rumen defaunating agents. Proc. Nutr. Soc. 43:154A.

Newbold, C. J., B. Lassalas, and J. P. Jouany. 1995. The importance of methanogens associated with ciliate protozoa in ruminal methane production in vitro. Lett. Appl. Microbiol. 21:230-234.

Nellot, L., D. Demeyer, and W. Verstracete. 1997. Effect of 2bromoethanesulfonic acid and Peptostreptococcus productus ATCC 35244 addition on stimulation of reductive acetogenesis in the ruminal ecosystem by selective by inhibition of methanogens. Appl. Environ. Microbiol. 63:194-200.

Patra, A. K., D. N. Kamra, and N. Agarwal. 2006. Effect of plant extracts on in vitro methanogenesis, enzyme activities and fermentation of feed in rumen liquor of buffalo. Anim. Feed Sci. Technol. 128:276-291.

Patra, A. K., D. N. Kamra, and N. Agarwal. 2006. Effect of spices on rumen fermentation, methanogenesis and protozoa counts in in vitro gas production test. Int. Congr. Ser. 1293:176-179.

Pilajun, R. and M. Wanapat. 2013. Microbial population in the rumen of swamp buffalo (Bubalus bubalis) as influenced by coconut oil and mangosteen peel supplementation. J. Anim. Physiol. Anim. Nutr. 97:439-445.

SAS. 2002. SAS User's Guide: Statistics. SAS Inst. Inc., Cary, NC, USA.

Theodorou, M. K., B. A. Williams, M. S. Dhanoa, A. B. McAllan, and J. France. 1994. A simple gas production method using a pressure transducer to determine the fermentation kinetics of ruminant feeds. Anim. Feed Sci. Technol. 48:185-197.

Vogels, G. D., W. F. Hoppe, and C. K. Stumm. 1980. Association of methanogenic bacteria with rumen ciliates. Appl. Environ. Microbiol. 40:608-612.

Woodward, S. L., G. C. Waghorn, M. J. Ulyatt, and K. R. Lassey. 2001. Early indication that feeding lotus will reduce methane emission from ruminants. Proc. NZ Soc. Anim. Prod. 61:23-26. 